1419 OCCUPATIONAL MEDICINE IN CHILE: CERTIFYING OCCUPATIONAL PHYSICIANS TOWARDS RECOGNITION, STRENGTHENING AND DEVELOPMENT OF THE MEDICAL SPECIALTY

1,2 Méndez José* 1,3 Cabrera Marta 1,2,3,4 Cubillos Bernardita 1,2,3,4,5 Urzú Ilse 1,2,3,4,5,6 Moreno Gabriela. 'Sociedad Chilena de Medicina del Trabajo, Santiago, Chile; ${ }^{2}$ Codelco Chile, División Andina, Los Andes, Chile; ${ }^{3}$ AngloAmerican, Santiago, Chile; ${ }^{4}$ Asociación Chilena de Seguridad, Santiago, Chile; ${ }^{5}$ Mutual de Seguridad, Santiago, Chile; ${ }^{6}$ Deutsche Pharma, Santiago, Chile

\subsection{6/oemed-2018-ICOHabstracts. 1054}

Introduction Occupational medicine is not formally recognised as a medical specialty in Chile and there are no clinical training programs in Chilean universities. Despite this situation, health authorities have developed occupational health protocols that give occupational physicians relevant roles and the Congress asked to strengthen occupational medicine to implement the National Safety and Health Policy. In absence of formal certification of specialists, the Chilean Society of Occupational Medicine has certified occupational physicians since 2014. This study aims to describe Chilean occupational physicians who are members of this association.

Methods 75 applications were received (2014-2016). 54 physicians $(72 \%)$ fulfilled the criteria to be certified as occupational physicians (59.3\% male) and the rest remained as collaborating members. An electronic survey was sent during January 2017 to collect information from members ( $85 \%$ response rate).

Results $78 \%$ of 46 physicians that answered the survey were 40 years or older and $74 \%$ had worked at least 10 years in occupational medicine. $87 \%$ got their medical degree in Chile and the rest in other Latin-American countries. 35\% $(n=16)$ have a medical specialty (public health $(n=5)$, occupational medicine $(n=3)$, rehabilitation medicine $(n=2))$. Occupational medicine specialists were trained abroad. One physician $(2 \%)$ has a doctoral degree; 32 (70\%) a master degree; $37(80 \%)$ a diploma certificate; 23 (50\%) completed other training programs. $72 \%$ completed 2 or more postgraduate programs; most referred were public health (29\%) and health management (20\%). 59\% declared more than one job, most usual were: management of occupational insurance (54\%), private companies (30\%), public institutions (28\%) and independent activity (24\%). $74 \%$ work in Santiago and 20\% in extreme north/south. 4\% work in shifts. 50\% also work in other than occupational medicine; $2 / 3$ have a management position; $39 \%$ teach; $15 \%$ do scientific research. $78 \%$ are 'highly satisfied/satisfied' with their current positions.

Discussion Occupational physicians in Chile are highly trained professionals with diverse academic background. Job positions are limited as the specialty does not formally exist. Standardisation of academic training is mandatory prior to recognition of the specialty and creation of specialty programs.

\section{PRINCIPLES OF FITNESS FOR DUTY EVALUATIONS}

${ }^{1,2}$ D Moyo*. ${ }^{1}$ Baines Occupational and Travel Medicine Centre, Harare, Zimbabwe; ${ }^{2}$ Midlands State University, Gweru, Zimbabwe

10.1136/oemed-2018-ICOHabstracts. 1055

Certifications for fitness for duty and return to work programs are an integral part of every medical practitioner' duties. Fitness for duty decisions have a direct impact on employee availability and productivity in the workplace. Increasing trends of sickness absenteeism, presenteeism and declining organisational wellness indices have become a common trend as a result of subjective and unsound fitness for duty and return to work evaluations. The increasing use of dysfunctional and out-dated principles of light duty, indefinite sick leave and unqualified medical retirement among others that are desynchronized with occupational risk exposure profiles and person job specifications requires urgent redress.

Fitness for duty decisions must take into account work processes, inherent job demands and attendant occupational risk profiles. These must be based on functional terms clarifying the restrictions and limitations in the face of workplace occupational exposures and job demands. The new approach of 'fit' notes versus sick leave notes has brought a new dimension in the return to work principles. The use of person job specifications, hazard identification and risk assessment methods and task analysis leads to an improvement of informed decision making for medical practitioners. Fitness for duty evaluations play a pivotal role in ensuring appropriate job placements and injury prevention. It is vital that medical practitioners apply the fundamental principles in assessing return to work and fitness for duty.

\section{SMOKING ADJUSTED INCIDENCE OF BLADDER CANCER USING PROXY SMOKING FROM LUNG CANCER IN NORDIC MALES}

${ }^{1}$ Kishor Hadkhale, ${ }^{2}$ Jan Iver Martinsen, $2,3,4,5$ Elisabete Weiderpass, ${ }^{2}$ Kristina Kjaerheim, ${ }^{6}$ Elsebeth Lynge, ${ }^{5}$ Pär Sparen, ${ }^{7,8}$ Laufey Tryggvadottir, ${ }^{1,9}$ Eero Pukkala. ${ }^{1}$ University of Tampere, Tempere, Finland; ${ }^{2}$ Department of Research, Cancer Registry of Norway, Institute of Population-Based Cancer Research, Oslo, Norway; ${ }^{3}$ Department of Community Medicine, Faculty of Health Sciences, University of Tromsø, The Arctic University of Norway, Tromso, Norway; ${ }^{4}$ Genetic Epidemiology Group, Folkhälsan Research Centre, Helsinki, Finland; ${ }^{5}$ Department of Medical Epidemiology and Biostatistics, Karolinska Institutet, Stockholm, Sweden; ${ }^{6}$ Center for Epidemiology and Screening, Institute of Public Health, University of Copenhagen, Copenhagen, Denmark; 'Tcelandic Cancer Registry, Reykjavik, Iceland; ${ }^{8}$ Faculty of Medicine, University of Iceland, Reykjavik, Iceland; ${ }^{9}$ Finnish Cancer Registry, Institute for Statistical and Epidemiological Cancer Research, Helsinki, Finland

\subsection{6/oemed-2018-ICOHabstracts. 1056}

Objectives The objective of this study was to observe the occupational variation in risk of bladder cancer that is not attributable to smoking.

Methods In the Nordic Occupational Cancer study (NOCCA), 111458 cases of bladder cancer and 208297 cases of lung cancer cases were observed among men in Denmark, Finland, Iceland, Norway and Sweden during 1961-2005. The expected numbers of bladder cancer in occupational category were corrected with smoking prevalence estimated on the basis of lung cancer risk in the category. Crude and smokingadjusted standardised incidence ratios (SIR) with 95\% confidence intervals (CI) were calculated for each occupation.

Results The smoking-adjusted SIR for most of the occupations was closer to 1.00 than the unadjusted SIR. It signifies the role of smoking as a risk factor of both bladder and lung cancers. Highest statistically significant smoking-adjusted SIRs were observed among chimney sweeps (SIR 1.33, 95\% CI: 1.08 to 1.61$)$, waiters $(1.18,1.04-1.34)$ hairdressers (1.16, $1.04-1.28)$, cooks and stewards $(1.13,1.01-1.27)$ and printers (1.10, 1.03-1.06).

Conclusion Smoking is a strong risk factor bladder cancer but there are other factors in some specific occupations in 
addition to smoking. The occupational variation in risk of bladder cancer is small when adjusted for smoking.

\section{EARLY MARKERS OF CARDIOVASCULAR DISEASE ARE ASSOCIATED WITH OCCUPATIONAL EXPOSURE TO POLYCYCLIC AROMATIC HYDROCARBONS}

${ }^{1}$ Ayman Alhamdow* ${ }^{*}{ }^{2}$ Christian Lindh, ${ }^{1,2}$ Maria Albin, ${ }^{1}$ Per Gustavsson, ${ }^{2}$ Håkan Tinnerberg,
${ }^{1,2}$ Karin Broberg. ${ }^{1}$ Karolinska Institutet, Stockholm, Sweden; ${ }^{2}$ Lund University, Lund, Sweden

10.1136/oemed-2018-ICOHabstracts. 1057

Introduction Occupational exposure to polycyclic aromatic hydrocarbons (PAH) from soot is common and has been associated with increased risk of cardiovascular disease (CVD); the association, however, has only been indicated, not established. Our aim was to investigate occupational exposure to PAH and early markers of CVD.

Methods A cross-sectional study of 151 chimney sweeps and 152 controls, all males, from Sweden was conducted between 2011-2015. Participants answered a questionnaire and gave blood and urine samples. Urinary PAH metabolites were measured using LC-MS/MS: 1-hydroxypyrene (1-OH-PYR), 2hydroxyphenanthrene (2-OH-PH), 3-hydroxybenzo[a]pyrene (3-OH-BaP), and 3-hydroxybenzo[a]anthracene (3-OH-BaA). Blood pressure (BP) and serum biomarkers were measured (Creactive protein, homocysteine, gamma-glutamyltransferase, cholesterol, HDL, LDL, and triglycerides), to estimate the risk of CVD.

Results Chimney sweeps had up to 7-fold higher concentrations of PAH metabolites in urine than controls $(p<0.001)$ : median concentrations (adjusted for specific gravity) for 1$\mathrm{OH}-\mathrm{PYR}, 2-\mathrm{OH}-\mathrm{PH}, 3-\mathrm{OH}-\mathrm{BaP}$, and $3-\mathrm{OH}-\mathrm{BaA}$ were $0.56 \mu \mathrm{g} /$ $\mathrm{L}, \quad 0.78 \mu \mathrm{g} / \mathrm{L}, \quad 4.75 \mathrm{ng} / \mathrm{L}$, and $6.28 \mathrm{ng} / \mathrm{L}$, respectively. $\mathrm{PAH}$ metabolites correlated positively with the amount of soot sweeping as a percentage of total work $(p<0.001)$. Chimney sweeps had increased homocysteine, cholesterol, and HDL $(\beta=3.4 \mu \mathrm{mol} / \mathrm{L}, 0.43 \mathrm{mmol} / \mathrm{L}$, and $0.13 \mathrm{mmol} / \mathrm{L}$, respectively, $\mathrm{p} \leq 0.003$, adjusted for age, BMI, and smoking). 2-OH-PH, 3$\mathrm{OH}-\mathrm{BaP}$, and 3-OH-BaA were positively associated with diastolic BP in chimney sweeps $(\mathrm{p}<0.044$, adjusted for age, BMI, and smoking).

Conclusions Working with soot resulted in clear exposure to $\mathrm{PAH}$, and in turn, an elevated risk for CVD. These findings indicate the need to raise awareness of protective measures that can decrease PAH exposure during work and in the general environment.

\section{OCCUPATIONAL ACCIDENTS REPORTED WITHIN THE FORENSIC MEDICINE DEPARTMENT}

D Lahlou*, I El Amri, B Benali, A Chbani, A Elkholti. Casablanca Faculty of medicine and pharmacy, Hassan II university, Morocco

\subsection{6/oemed-2018-ICOHabstracts. 1058}

Introduction Professions in health care settings are characterised as having a high professional risk, in addition tohealth care workers, all occupations are carried out with specific constraints, exposing personnel to several risks, due to accidents involving exposure to biological products, physical nuisance, chemical toxicity and stress.
Materials and methods Our work consists of a retrospective study of 119 cases of occupational accidents declared by staff (3684 employees) of the Ibn Rochd University Hospital in Casablanca, over a period of 3 years (between January 2010 and December 2012).

Results Ninety women and twenty ninemen were enumerated, with a sex ratio of 0.32 .The average age was 45.58 years, with extremes of 23 to 60 years.

Nurses and nursing assistants represent $42,01 \%$ of the cases, followed by service agents (31\%), then doctors $(15,12 \%)$. Administrative personnel remainsas the least the exposed category $(6,72 \%)$.

The most frequent accidents are related to falls $(52,08 \%)$, followed by blood exposure (18,48\%), while musculoskeletal disorders come far after with a percentage of $3.36 \%$. The temporary work disability, stands between 3 days and 3 months, with a prolongation that can go up to 12 months. Thenumber of patient who had a permanentpartial disability was 28 , with rates varying from $2 \%$ to $18 \%$. None of them needed a job change orreclassification.

Conclusion Hospital staff is exposed to a number of risks, this requires taking somenecessarymeasures to ensure the safety and protect the health of healthcare workers, taking as a base general principles of prevention.

\section{SELF-DETERMINING MEDICAL LEADERSHIP NEEDS OF OCCUPATIONAL MEDICINE PHYSICIANS - A STUDY THAT CAN RESHAPE THE MEDICAL LEADERSHIP TRAINING}

1,2,3Prosenjit Giri* ${ }^{3}{ }^{3}$ Jill Aylott, ${ }^{4}$ Karen Kilner. ${ }^{1}$ Sheffield Teaching Hospitals Nhs Trust, Worksop, UK; ${ }^{2}$ Sheffield University, UK; ${ }^{3}$ International Academy of Medical Leadership, Dronfield, Derbyshire, UK; ${ }^{4}$ Centre for Leadership in Health and Social Care, Sheffield Hallam University, Sheffield, UK

\subsection{6/oemed-2018-ICOHabstracts. 1059}

Introduction Physician leadership, irrespective of hierarchy, is an integral part of delivering complex modern-day healthcare which thrives on quality improvement and efficiency savings. Doctors' participation in Medical Leadership however remains fragmented and patchy as has been their leadership training. Absence of empirical research in designing strategies to engage and motivate doctors and validated leadership qualities assessment instruments may have compounded the problem further. Methods This national study, facilitated by the Faculty of Occupational Medicine of the UK (FOM), explored factors that motivate the UK-based Occupational Medicine Physicians (OHPs) to engage in leadership roles alongside assessment of their leadership competency and training needs by framing an inquiry within Self-Determination Theory using the 7 domain National Health Service Leadership Academy self-assessment tools on a web-based platform. The data were analysed using descriptive statistics and simple inferential methods.

Results 25\% (250/1000) of the UK-based FOM $(n=1000)$ members participated. OHPs were open about reporting their leadership strengths (mean score; $4.26 / 8$ across 7 domains; highest in personal qualities; 5.77/8 and lowest in Creating the Vision; 2.73/8). Irrespective of personal level of competency, they universally recognised the need for life-long leadership training. Experience of management role (6 domains; $\mathrm{p}<0.05)$ was identified as the single most influencing factor behind a doctor's confidence. In multivariate regression, management experience accounted for the usefulness of leadership 